\title{
Development of Marine Propellers with Better Cavitation Performance
}

\author{
-3rd Report : Pressure distribution to stabilize cavitation- \\ by Hajime Yamaguchi*, Member \\ Atsufumi Sugatani**, Member \\ Takuei Honda*** \\ Hiroharu Kato*, Member \\ Akihiro Kamijo*** \\ Masatsugu Maeda*
}

\begin{abstract}
Summary
This paper deals with pressure distribution which becomes effective when the propeller works in a severe condition resulting in the generation of harmful cloud cavitation. In such a case, it is considered that a way to stabilize sheet cavity and suppress cloud cavitation is more promising than the usual way to reduce the amount of cavity. Since pressure fluctuations induced by a cavitating propeller are mainly due to time variation of cavity volume, such an approach has a probability of not only suppressing erosion but also reducing pressure fluctuations.

Using a propeller design method developed in previous reports, two propellers were designed and tested at a condition where the original MAU type propeller generated cloud cavitation and erosion. One propeller had flat pressure distribution which was proved effective at a condition of no cloud cavitation in the previous reports. The other had triangular pressure distribution with a negative peak at the leading edge and a gentle pressure recovery towards the trailing edge to stabilize sheet cavitation and reduce its volume variation. The experimental results showed that the triangular pressure distribution propeller succeeded in suppressing the cloud cavitation completely while the flat one failed. However, neither cavity volume variation nor pressure fluctuations were lessened by the triangular pressure distribution although almost the same levels were kept in both the pressure fluctuations and noise.

Thus two-dimensional and quasi-steady study was performed to obtain a prospect for the pressure distribution which stabilizes sheet cavitation and also reduces its volume variation due to the change of the angle of attack. Two foil sections with a negative pressure peak at the leading edge and a region of constant pressure which is lower than the vapor pressure were designed with theoretical predictions by boundary layer and nonlinear cavity flow calculations. Comparative experiments to an existing MAU type section result showed that the new foil sections much lessen the cavity volume variation due to the angle of attack. They have a possibility of reducing the fluctuating pressure amplitude to less than half of that of the MAU section in addition to suppressing cloud cavitation.
\end{abstract}

\section{Nomenclature}

$C_{p}:$ Pressure coefficient normalized by the uniform flow velocity

$C_{p n}:$ Propeller pressure coefficient

* Department of Naval Architecture, The University of Tokyo

** Kawasaki Heavy Industries, Co. (Graduate School, Department of Naval Architecture, The University of Tokyo during this work)

*** Graduate School, Department of Naval Architecture, The University of Tokyo

$$
\left(=\left(P-P_{o}\right) /\left(\rho n^{2} D^{2} / 2\right)\right)
$$

$D$ : Propeller diameter

$H$ : Propeller pitch based on the nose-tail line

$J$ : Propeller advance coefficient

$J_{\max }: J$ based on the maximum velocity of the wake

$J_{\text {mean }}: J$ based on the mean velocity of the wake

$J_{\min }: J$ based on the minimum velocity of the wake

$K_{T}$ : Propeller thrust coefficient

$K_{Q}:$ Propeller torque coefficient

$K_{p z}$ : Nondimensional fluctuating pressure amplitude at $z$-th order $\left(=\Delta P_{z} /\left(\rho n^{2} D^{2}\right)\right)$ 
$L$ : Cavity length normalized by the chord length of the foil

$n$ : Number of propeller revolution

$P:$ Static pressure

$P_{0}:$ Static pressure at the propeller shaft center

$P_{v}:$ Vapor pressure

$r$ : Propeller radius position

$R$ : Propeller radius

$R_{n D}$ : Reynolds number based on the propeller diameter $\left(=n D^{2} / \nu\right)$

$R_{n C}$ : Reynolds number based on the chord length of the foil and the uniform flow velocity

$T$ : Maximum cavity thickness normalized by the chord length of the foil

$t$ : Time

$V$ : Cavity volume (sectional area in reality since this is used in the foil section case) normalized by the chord length of the foil

$w:$ Wake fraction

$\alpha$ : Angle of attack relative to the zero-lift line

$\alpha^{\prime}$ : Angle of attack relative to the nose-tail line

$\alpha / \alpha_{s}$ : Air content ratio of the water to the saturated condition at 1 atm

$\Delta P_{z}$ : Single amplitude of fluctuating pressure at $z$-th order

$\eta_{0}:$ Propeller open efficiency

$\nu$ : Kinematic viscosity of water

$\rho:$ Density of water

$\sigma:$ Cavitation number based on the uniform flow velocity

$\sigma_{n}$ : Propeller cavitation number $\left(=\left(P_{o}-P_{v}\right) /\left(\rho n^{2} D^{2} / 2\right)\right)$

$\phi_{z}$ : Phase delay of the fluctuating pressure at $z$-th order from the blade position of $\Psi=0^{\circ}$

$\Psi$ : Propeller blade angle position

$\omega$ : Circular frequency of the angle of attack oscillation

(Superscript)

* : Specially used for the values of the foil section TP 713. Since this section is designed with assuming the chord length reduction to $3 / 4$ of those of the other sections, the comparison to the other sections is made in such a way that $\alpha^{*}=$ $(3 / 4) a^{\prime}, \quad L^{*}=(3 / 4) L, \quad T^{*}=(3 / 4) T \quad$ and $V^{*}=(9 / 16) V$.

\section{Introduction}

In previous papers ${ }^{1)}{ }^{3)}$, the authors proposed a new propeller design method where blade section shapes with prescribed pressure distribution can be obtained by combining Eppler's 2-dimensional foil design theory ${ }^{4)}$ with Hanaoka and Koyama's propeller lifting surface on $\mathrm{e}^{5)}$. Using this design method, it was shown that the flat pressure distribution lessens cavitation noise and pressure fluctuations by reducing the cavity volume and its time variation and raises propeller efficiency by suppressing the boundary layer development. The effects of design lift coefficient where the pressure distribution becomes flat were also investigated by designing propellers with different design lift coefficients and performing comparative experiments with the original MAU type propeller.

These studies were, however, performed at the conditions where both the original MAU type and the new propellers generated no cloud cavitation. In case of a severe condition where sheet cavity collapses towards the trailing edge with giving harmful cloud cavitation, it is considered that the flat pressure distribution is not effective since the wide low pressure region might carry the sheet cavity to the high pressure trailing edge area with little volume reduction, resulting in violent collapse of the sheet cavity. In such a case, it might become effective to aim directly at stabilizing the sheet cavity to suppress the cloud cavitation and reducing the time variation of cavity volume to decrease the pressure fluctuations, even if it gives more volume of sheet cavity. Although Ligtelijn and Kuiper6) also pointed out the importance of stabilizing cavity and decreasing its volume variation based on their own experiences, it has not yet known or verified what kind of pressure distribution can attain the present purpose. In this research, therefore, two propellers are newly designed and tested at a condition where the original MAU type propeller generates cloud cavitation and erosion. One propeller with flat pressure distribu. tion was designed to verify whether the flat pressure distribution is really ineffective to the suppres. sion of cloud cavitation. The other with triangular pressure distribution was designed to stabilize sheet cavity and reduce its time variation by the negative pressure peak at the leading edge and the monotonous pressure increase towards the trailing edge. Regarding the effect on cloud cavitation, the experimental result agreed with the expectation, i. e. the propeller with triangular pressure distribution did not generate cloud cavitation at all while the propeller with flat one generated it. Regarding the pressure fluctuations, however, the expected results were not obtained. Neither the cavity volume variation nor the pressure fluctuations were reduced by the triangular pressure distribution, although there was little increase in the pressure fluctuations and noise in spite of the cavity volume being about three times as large as that of the original MAU type propeller.

Then two-dimensional and quasi-steady study on foil sections was performed to obtain a prospect for the pressure distribution which stabilizes sheet 
Table 1 Principal particulars of model propellers

\begin{tabular}{|c|c|c|c|}
\hline Propeller No. & MP002 & MP013 & 10014 \\
\hline Diameter $(\mathrm{mm})$ & \multicolumn{3}{|c|}{214.29} \\
\hline Pitch Ratio & $\begin{array}{c}0.800 \\
\text { (constant, base line) }\end{array}$ & $\begin{array}{c}0.842 \text { at } 0.7 R \\
(\text { variable) }\end{array}$ & $\begin{array}{l}0.933 \text { at } 0.7 \mathrm{R} \\
(\text { variable) }\end{array}$ \\
\hline Expanded Area Ratio & \multicolumn{3}{|c|}{0.600} \\
\hline Boss Ratio & \multicolumn{3}{|c|}{0.18} \\
\hline Blade Thickness Ratio & \multicolumn{3}{|c|}{0.07} \\
\hline Number of Blades & \multicolumn{3}{|c|}{4} \\
\hline Rake Angle & \multicolumn{3}{|c|}{$10^{\circ}$} \\
\hline Blade Contour & \multicolumn{3}{|c|}{$\mathrm{AU}$} \\
\hline \multirow{2}{*}{ Blade Section } & \multirow{2}{*}{ MAU } & UTOP-4 & UTOP -5 \\
\hline & & \multicolumn{2}{|c|}{ ( Newly Designed) } \\
\hline Remarks & $\begin{array}{c}\text { Original MAU Type } \\
\text { Prop. }\end{array}$ & $\begin{array}{c}\text { Flat Pressure } \\
\text { Distribution Prop. }\end{array}$ & $\begin{array}{l}\text { Triangular Pressure } \\
\text { Distribution Prop. }\end{array}$ \\
\hline
\end{tabular}

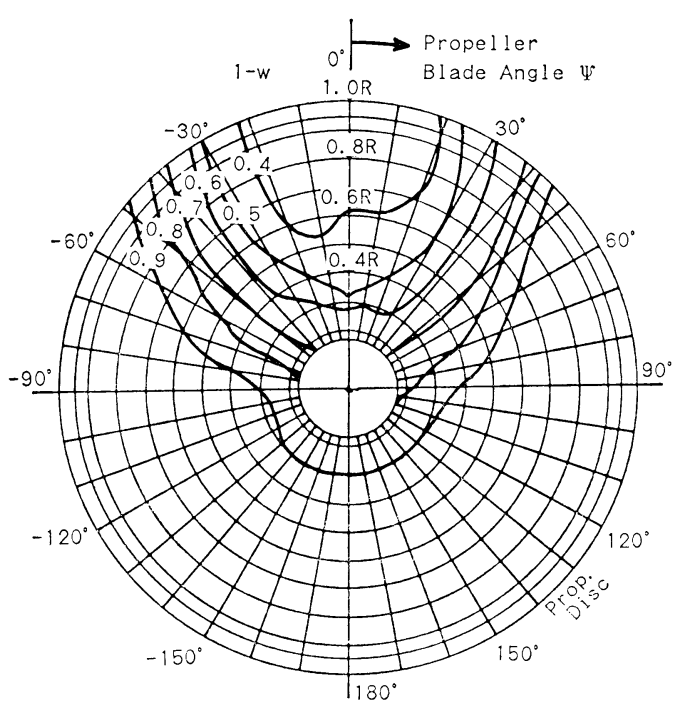

Fig. 1 Wake distribution

cavitation and also reduces its volume variation due to the change of the angle of attack. In this study, cavitation performance of the new foil sections was predicted in detail by the calculations using boundary layer theory and nonlinear cavity flow one developed by the authors ${ }^{7)}$ () and verified by the experiments.

\section{Effect of a Propeller with Triangular Pressure Distribution}

\subsection{Propeller design and its aim}

A MAU type propeller MP 002, which was used in the previous report ${ }^{3}$, was adopted also here as the original propeller. The principal particulars are shown in Table 1 together with those of the new propellers. These new propellers were designed by the same procedure as described in the previous report ${ }^{3)}$ except for the thickness modification in the rear part of the blade sections. In the present case, the thickness line after the maximum thickness point was smoothly expanded by a quadratic expression to obtain the same trailing edge thickness as the MAU type one. The same treatment was made on the foil sections in the next chapter. This modification was adopted to realize the hoped pressure distribution more exactly although the thickness near the trailing edge became thinner compared with those by the method in the previous report ${ }^{3)}$. This is not essential problem, however, and more practical section shapes can be obtained by the previous method without significant change in the pressure distribution.

The design point was selected as

$$
K_{T} / J^{2}=0.425, \sigma_{n} / J^{2}=4.08
$$

$\left(J=0.60, \quad K_{T}=0.152, \quad \sigma_{n}=1.47\right.$ in the case of MP 002)

in the wake distribution shown in Fig. 1. Compared with the design point in the previous report $^{3}$, $K_{T} / J^{2}=0.552$ and $\sigma_{n} / J^{2}=6.49\left(J=0.555, \quad K_{T}=0.170\right.$ and $\sigma_{n}=2.00$ ), the present design point is more severe to cavitation with the cavitation number reduced to about 0.6 times the previous one. At this working condition, MP 002 generates cloud cavitation near the trailing edge as shown in Fig. 8 of the next section. Figure 2 shows the pressure distribution at $0.8 \mathrm{R}$ position of MP 002 obtained from the lifting surface calculations using the Hanaoka-Koyama's theory ${ }^{5)}$ and the equivalent twodimensional foil concept. In this figure, the curves of $J=J_{\text {mean }}$ correspond to the condition in the mean wake, while those of $J=J_{\min }$ and $J_{\max }$ correspond to the most and the least loaded conditions in the wake, respectively. It is considered that the cloud cavitation on this propeller is mainly due to the hill of negative pressure near the midchord on the back surface.

Two propellers MP 013 and MP 014 were newly 


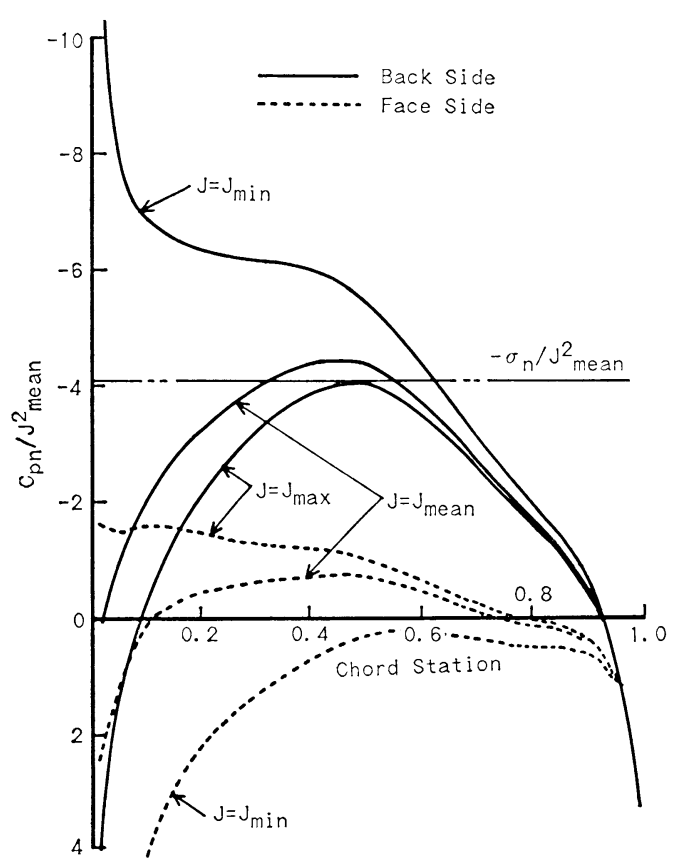

Fig. 2 Steady state pressure distributions at $0.8 \mathrm{R}$ position using mean, minimum and maximum velocity of the wake; MP 002 (MAU)

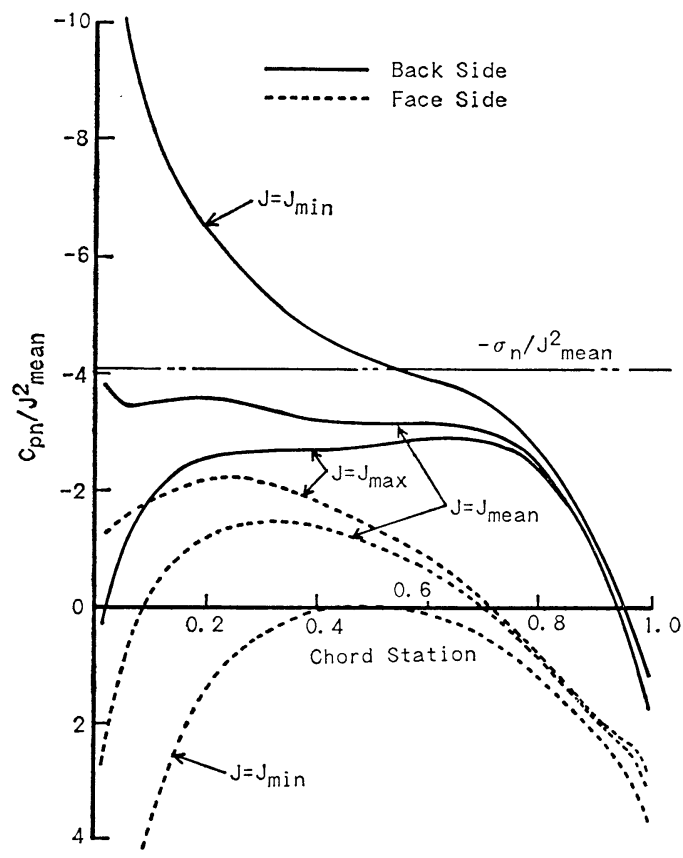

Fig. 3 Steady state pressure distributions at $0.8 \mathrm{R}$ position using mean, minimum and maximum velocity of the wake; MP 013

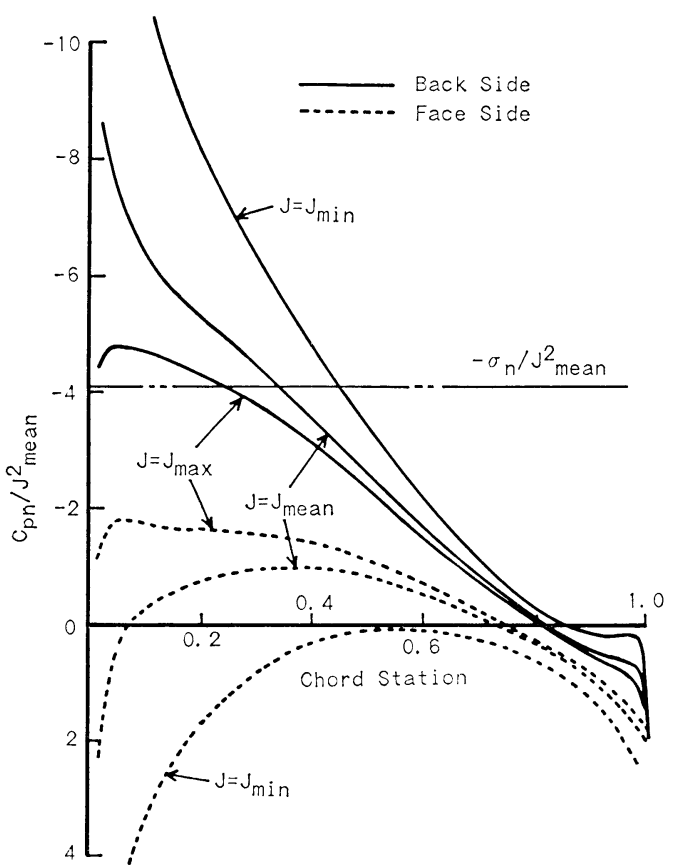

Fig. 4 Steady state pressure distributions at $0.8 \mathrm{R}$ position using mean, minimum and maximum velocity of the wake; MP 014

designed for this severe condition to cavitation. As shown in Fig. 3, MP 013 has flat pressure distribution similarly to the propellers in the previous report ${ }^{3)}$. In the present case, however, the lower cavitation number violated some of the design criteria denoted in Fig. 9 of the previous report and the criteria of the design lift coefficient obtained from the experiment. They are as follows:

(1) the difference between the flat part and the vapor pressure is small,

(2) the pressure recovery region near the trailing edge is too short, and

(3) the design lift coefficient is too low as can be seen from the negative pressure peak at the leading edge occurring even in the case of $J=$ $J_{\text {mean }}$; this propeller might generate more cavitation than MP 002.

It is evident, however, that MP 013 has the characteristics of flat pressure distribution. This propeller was designed to verify the ineffectiveness on the suppression of cloud cavitation described in the preceding chapter. On the other hand, MP 014 has triangular pressure distribution as shown in Fig. 4. Although this propeller is predicted to generate cavitation during the whole blade revolution, the following two effects are expected from the intentional negative pressure peak at the leading edge and the monotonous pressure increase towards the trailing edge :

(1) to suppress the cloud cavitation by stabiliz- 


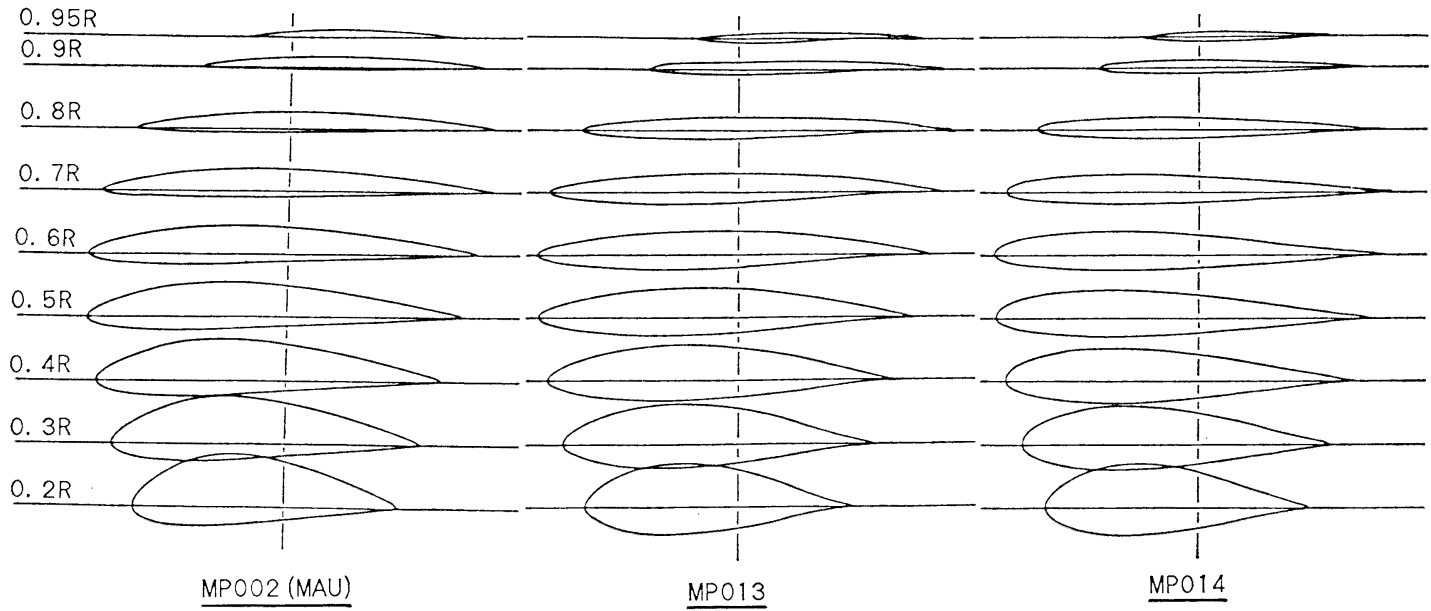

Fig. 5 Propeller section shapes

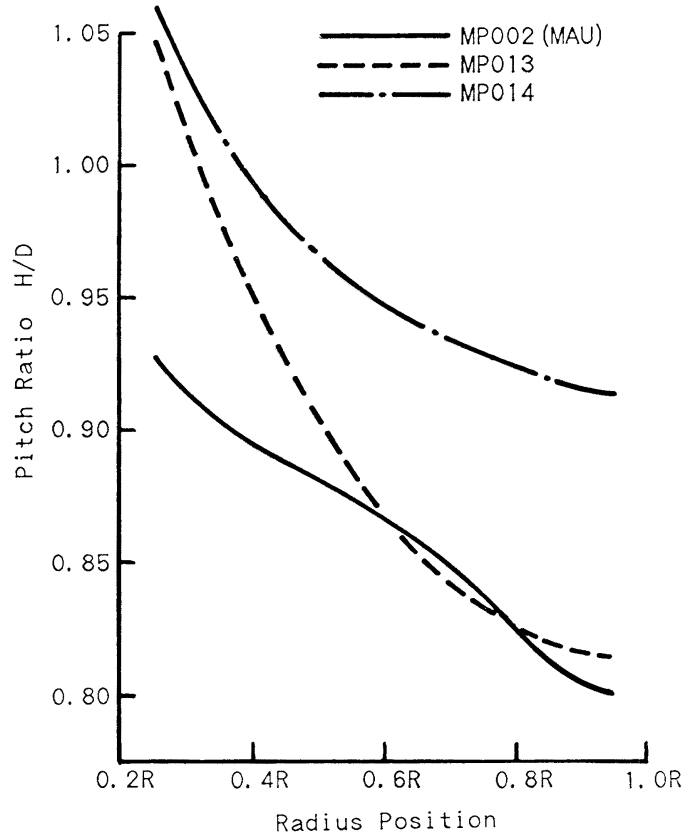

Fig. 6 Pitch distributions

ing the sheet cavitation, and

(2) to diminish the pressure fluctuations by reducing the cavity volume variation.

The principal particulars, the blade section shapes and the pitch distributions of all the propellers are respectively shown in Table 1, and Figs. 5 and 6 . The new propellers are different from the original one MP 002 only in the section shapes and the pitch distributions. The latter was determined to give the same loading distribution in the radial direction as that of MP002, similarly to the propellers in the previous report ${ }^{3)}$. The higher loading in the rear part of MP 013 raises the camber there parti-

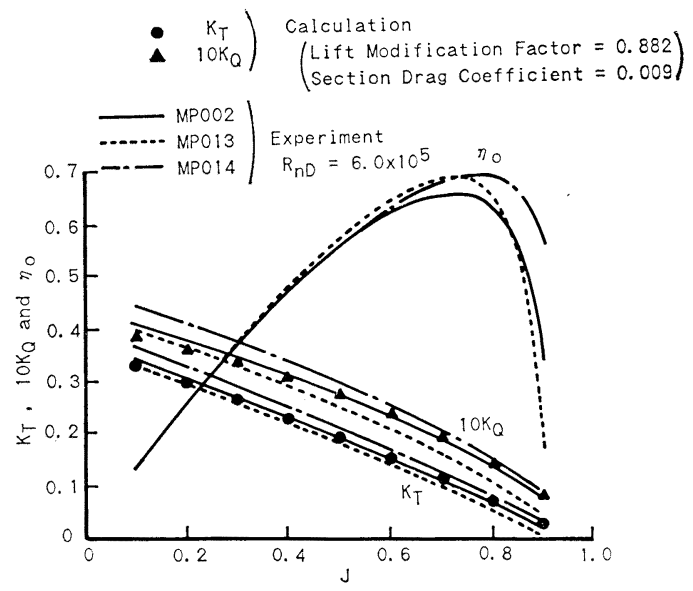

Fig. 7 Propeller open characteristics

cularly near the tip and MP 014 generates its thrust mainly by the pitch.

\section{2 Experimental results}

Propeller open tests were made at the Large Towing Tank of Akishima Laboratories (Mitsui Zosen) Inc. with the propeller Reynolds number $R_{n D}$ of 6. $0 \times 10^{5}$. The results are shown in Fig. 7 together with the lifting surface calculation results. It is seen that the calculated results agree very well with the experimental ones of the MAU type propeller MP 002. The reduction in thrust and torque of MP 013 is considered due to the trailing edge separation as experienced in the beginning stage of this series of research ${ }^{1), 2}$. The reason for the increase in thrust and torque of MP 014 is not clear yet. It might be due to the fact that the chordwise loading distribution of this propeller is quite different from those of the others, as shown in Figs. 2 through 4.

Cavitation experiments were performed at the 

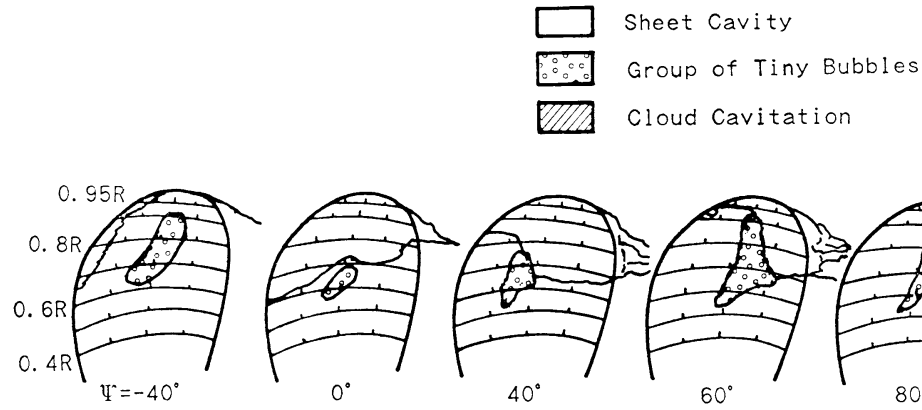

1) MPOO2 (MAU)
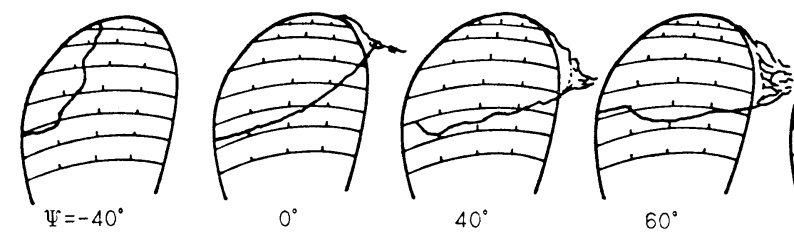

$40^{\circ}$

$60^{\circ}$

2) MP013

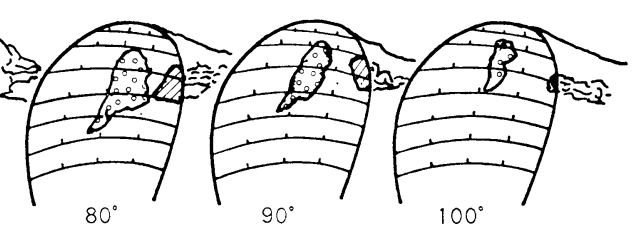

$100^{\circ}$
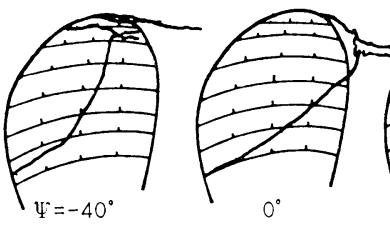

$0^{\circ}$

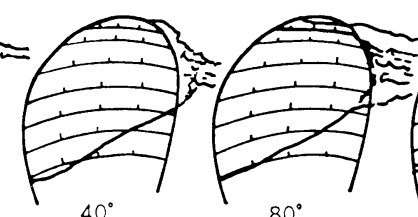

$40^{\circ}$

3) MPO14

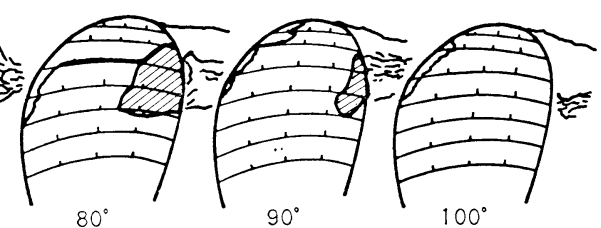

$80^{\circ}$

$90^{\circ}$

$100^{\circ}$

Fig. 8 Comparison of cavity pattern in the wake; Design Point $\left(K_{T} / J^{2}=0.425, \sigma_{n} / J^{2}=4.08\right)$, $n=32.0 \mathrm{rps}$

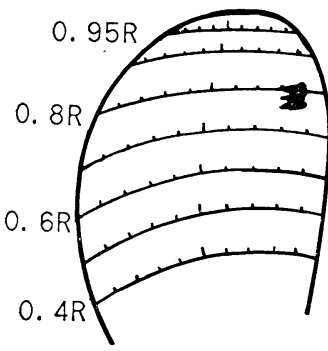

1) MPOO2 (MAU)

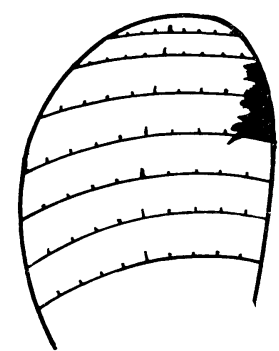

2) MP013

Fig. 9 Paint test results (no paint peeling off on MP 014); Design Point $\left(K_{T} / J^{2}=0.425\right.$, $\left.\sigma_{n} / J^{2}=4.08\right), \quad n=32.0 \mathrm{rps}$

Marine Propeller Cavitation Tunnel of the University of Tokyo ${ }^{11)}$. The working section is a square of $450 \mathrm{~mm}$ and the wake shown in Fig. 1 was simulated by a wire mesh screen. Although experiments were also carried out in uniform flow ard at other test conditions ${ }^{12)}$, only the results at the cesign point in the wake are described here. These experiments were carried out at a propeller revolution rate of $32 \mathrm{rps}$. In order to reduce the cavitation intermittency, steel powder of $90-160 \mu \mathrm{m}$ in diameter was distributed near the leading edge of the propellers and the air content of the water

was controlled to keep the saturated condition at the test section pressure, similarly to the experiments in the previous reports ${ }^{1)} \sim^{3)}$.

Figure 8 shows the comparison of cavitation pattern. As aforementioned, the original MAU type propeller MP 002 generated cloud cavitation. A group of tiny bubbles observed near the center of the blade is considered due to the hill of negative pressure shown in Fig. 2, which also causes the cloud cavitation. MP 013 generates violent cloud cavitation as predicted. Larger sheet cavitation on this propeller is caused by the too low design lift coefficient which also causes the more violent cloud cavitation. On the contrary, MP 014 did not generate cloud cavitation at all as expected although the sheet cavity became larger and always occurred during the whole blade revolution. The results of 30 minute paint tests using marking paint "Aotak"13) are shown in Fig. 9 as the erosion indicator. The paint peeling off region is denoted by the black area in the figure. It can be seen that the paint on MP 002 and MP 013 peeled off where the cloud cavitation was observed. On the other hand, the paint on MP 014 did not peel off at all. It can be said, therefore, that the aforementioned first aim of this propeller has been achieved.

The cavitating propeller efficiency in the wake 


\begin{tabular}{|c|c|l|}
\hline No-Cavi. & \multicolumn{2}{|c|}{ Cavi. } \\
\hline \multirow{3}{*}{$\times$} & $\bullet$ & MP002 (MAU) \\
\cline { 2 - 3 } & $\Delta$ & MP013 \\
\cline { 2 - 3 } & $\mathbf{a}$ & MP014 \\
\hline
\end{tabular}
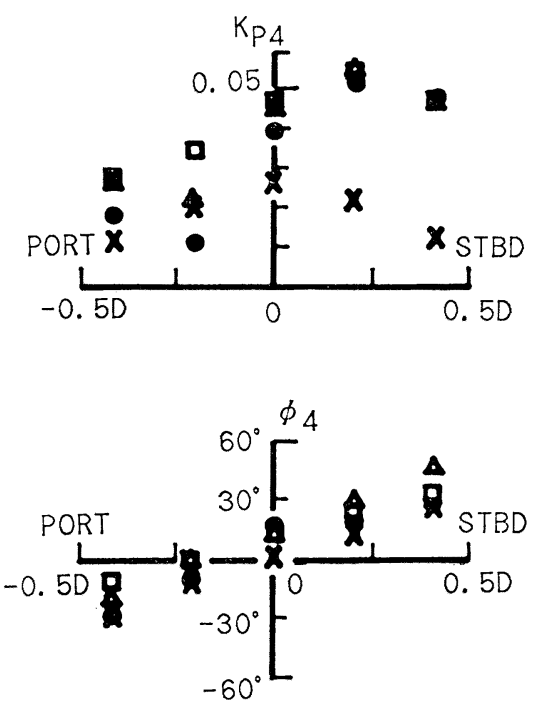

1) Transverse Distribution
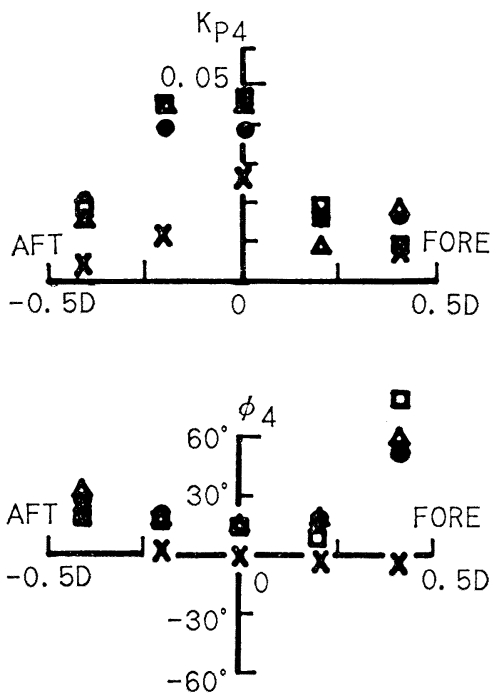

2) Longitudinal Distribution

Fig. 10 Comparison of fluctuating pressure amplitude and phase angle at the 1 st blade frequency; Design Point $\left(K_{T} / J^{2}=0.425, \sigma_{n} / J^{2}=4.08\right), n=32.0 \mathrm{rps}$

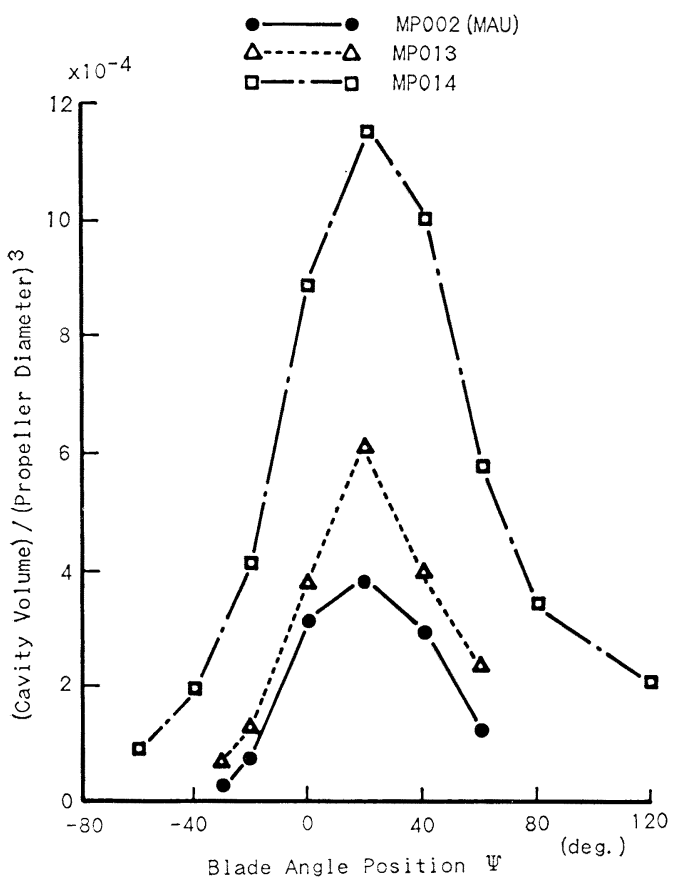

Fig. 11 Comparison of cavity volume variation; Design Point $\left(K_{T} / J^{2}=0.425, \sigma_{n} / J^{2}=4.08\right)$, $n=32.0 \mathrm{rps}$ was evaluated from the thrust and torque values measured at the cavitation tunnel under the condition of no leading edge roughness. The advance coefficient $J$ was obtained from the propeller open test results on the basis of thrust identity. The propeller efficiencies of MP002(MAU), MP013 and MP014 were $0.609,0.608$ and 0.592 respectively at the propeller Reynolds number $R_{n D}$ of 1.3 $\times 10^{6}$. The slight efficiency drep of MP 014 is considered due to the larger cavity generated and might be diminished by adopting the design to reduce cavity at the inner radii. The efficiency drop might be a kind of compensation for suppressing the cloud cavitation.

The fluctuating pressure due to propellers was measured by the same apparatus that was used in the previous study ${ }^{3)}$, viz. measured by the pressure transducers mounted in a cross formation on a horizontal flat plate which was installed above the model propeller. The tip clearance was about 0.26 times the propeller diameter. Figure 10 shows the comparison of amplitude and phase angle of the fluctuating pressure at the 1 st blade frequency, together with the results in noncavitating condition. Regarding the higher frequency components, no significant difference among the propellers was otained with very low level of nondimension- 
al amplitude which was about 0.01 at the maximum. As can be seen in this figure, the fluctuating pressure amplitude of the new propellers MP 013 and MP 014 was slightly larger than that of MP 002. The increase in the pressure fluctuations of MP 013 is ascribable to the too low design lift coefficient as seen also in the case of MP 016 of the previous report ${ }^{3)}$. The reason for the unexpected results of MP 014 can be elucidated by the cavity volume variation. Figure 11 compares the variation of cavity volume obtained by integrating the cavity thickness measured by a pin gauge method ${ }^{14)}$ similarly to the previous report. It can be seen that MP014 gave only the increase in the cavity volume and no reduction of its time variation contrary to the expectation. Of course, this propeller can be positively evaluated as it suppressed cloud cavitation and erosion with little increase in the pressure fluctuations in spite of generating about three times as large cavity as the original MAU type propeller. It can be concluded, however, that the triangular pressure distribution could not reduce the cavity volume variation or the pressure fluctuations.

The cavitation noise was measured by the same instruments and at the same position as those in the previous report ${ }^{3)}$, viz. by a B \& K 8103 type hydrophone placed at the position of $\Psi=75.1^{\circ}$ (starboard side) and $r=1.535 R$ in the propeller plane inside the cavitation tuninel. The results are shown in Fig. 12. The noise level of MP 014 agreed approximately with that of MP 002 although MP 014 gererated much larger cavity. This is also considered due to suppressing the cloud cavitation.

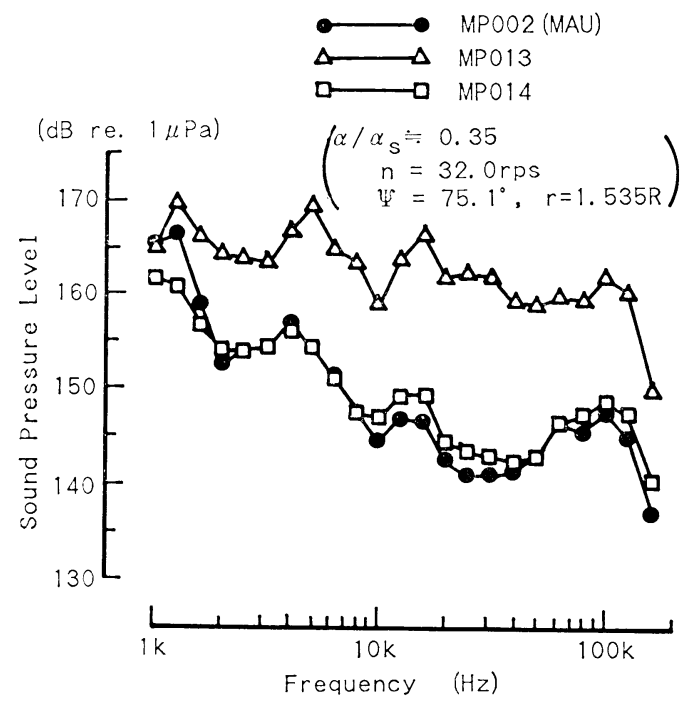

Fig. 12 Comparison of cavitation noise; Design Point $\left(K_{T} / J^{2}=0.425, \quad \sigma_{n} / J^{2}=4.08\right), \quad n=$ $32.0 \mathrm{rps}$

\section{Development of Foil Sections with Less Cavity Volume Variation against the Angle of Attack Variation}

\subsection{Design of foil sections}

Since the triangular pressure distribution propeller failed to reduce the cavity volume variation, a fundamental study on two-dimensional foils was performed to obtain a prospect for the pressure distribution which both stabilizes sheet cavitation and reduces its volume variation due to the angle of attack. Although unsteady approach with the angle of attack variation taken into account is more exact, quasi-steady assumption was adopted in this study because of the ability of the experimental facilities and the theoretical calculation programs used for prediction. Thus, all the calculations and the experiments were made on a foil fixed in uniform flow.

Figure 13 is a schematic explanation of the pressure distribution aimed here. The concepts of this pressure distribution are as follows :

(1) Negative pressure peak with laminar separation or turbulent transition is given at the leading edge even in low angle of attack in order to stabilize sheet cavitation.

(2) A region of constant pressure which is lower than the vapor one is given at the low angle of attack in order to increase the minimum cavity size.

(3) Pressure recovery following the constant pressure region is taken steep within the limit of

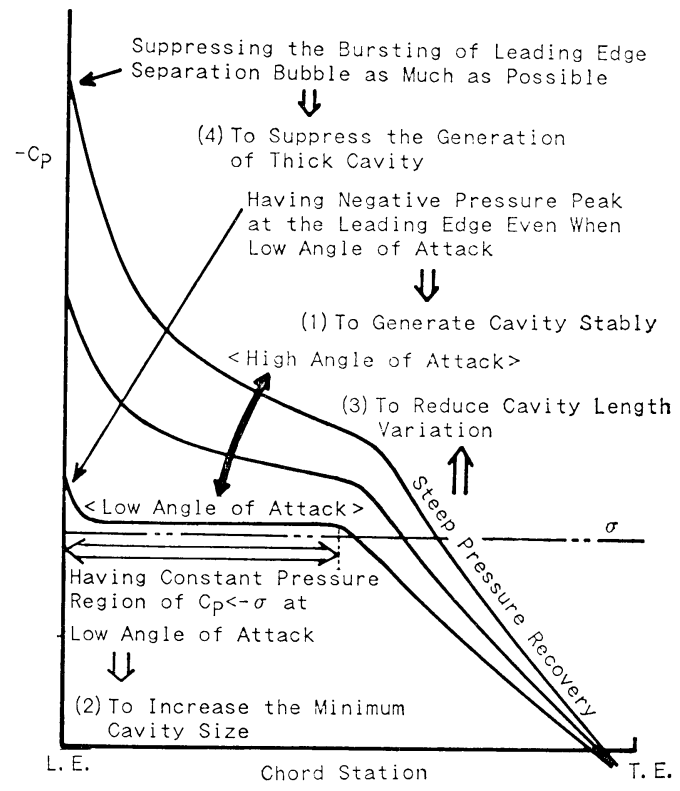

Fig. 13 Pressure distribution to reduce cavity volume variation due to angle of attack 


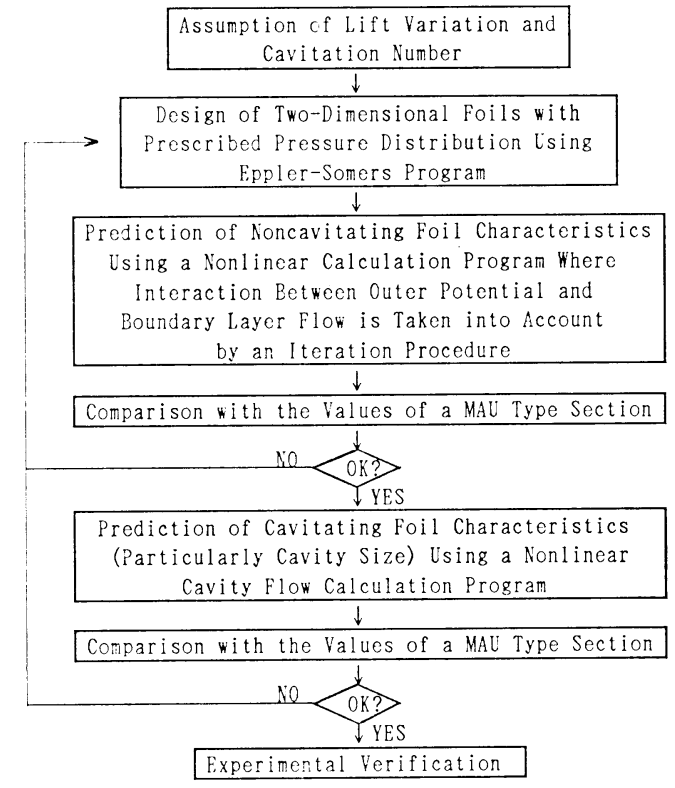

Fig. 14 Flow chart of developing two-dimensional foils with less cavity volume variation; Performed with quasi-steady assumption

no turbulent separation in order to reduce the cavity length variation.

(4) The angle of attack where the bursting of the leading edge separation bubble begins to occur is taken as high as possible since the separation bubble bursting leads to thicker cavity particularly in the fore part $\left.\left.{ }^{2)}, 10\right), 15\right)$.

A prudential procedure shown in Fig. 14 was adopted since opposite requirements (1) and (4) are included. First, the boundary layer characteristics were predicted using an iteration procedure where potential flow calculation by surface sourcevortex distribution similar to Hess-Smith method $^{7 / 9), 16)}$ was incorporated with boundary layer calculation using Thwaites' method modified by Curle and Skan (laminar boundary layer and its separation), Smith and Cebeci's method (transition point), and Head's method modified by Cebeci (turbulent boundary layer), on the basis of displacement body concept ${ }^{17)}$. In this process particular attention was paid to the leading edge separation and its bursting, and the turbulent separation in the pressure recovery region. Then a nonlinear partial cavitation theory developed by the authors ${ }^{7)}$ (8).9) was used to predict the cavitation performance, particularly cavity volume and its variation due to the angle of attack.

MAU 0.8R (MESK) Section with the thickness ratio of $6 \%$ (to be called MAU Section here) was selected for comparison since the experimental data were available ${ }^{21,10)}$. Taking into consideration the camber reduction due to the three-dimensional effects of propeller flow ${ }^{18)}$, the camber line of this foil section was reduced to 0.7 times the original MAU type one. In designing new foil sections, the cavitation number and lift variation, (working range) were assumed as $\sigma=0.4$ and $\alpha=2 \sim 6^{3}$, where $\sigma$ and $\alpha$ are cavitation number based on the uniform flow velocity and angle of attack relative to the zero-lift line, respectively. Hence $\alpha$ can be converted into lift coefficient $C_{L}$ by $C_{L}=2 \pi \alpha$. The assumed cavitation number of 0.4 is much higher compared with the previous propeller one since the cavitation number based on the inflow velocity to the $0.8 \mathrm{R}$ blade section was about 0.22 . The cavitation number of 0.4 , however, was adopted owing to the ability of the cavitation tunrel and

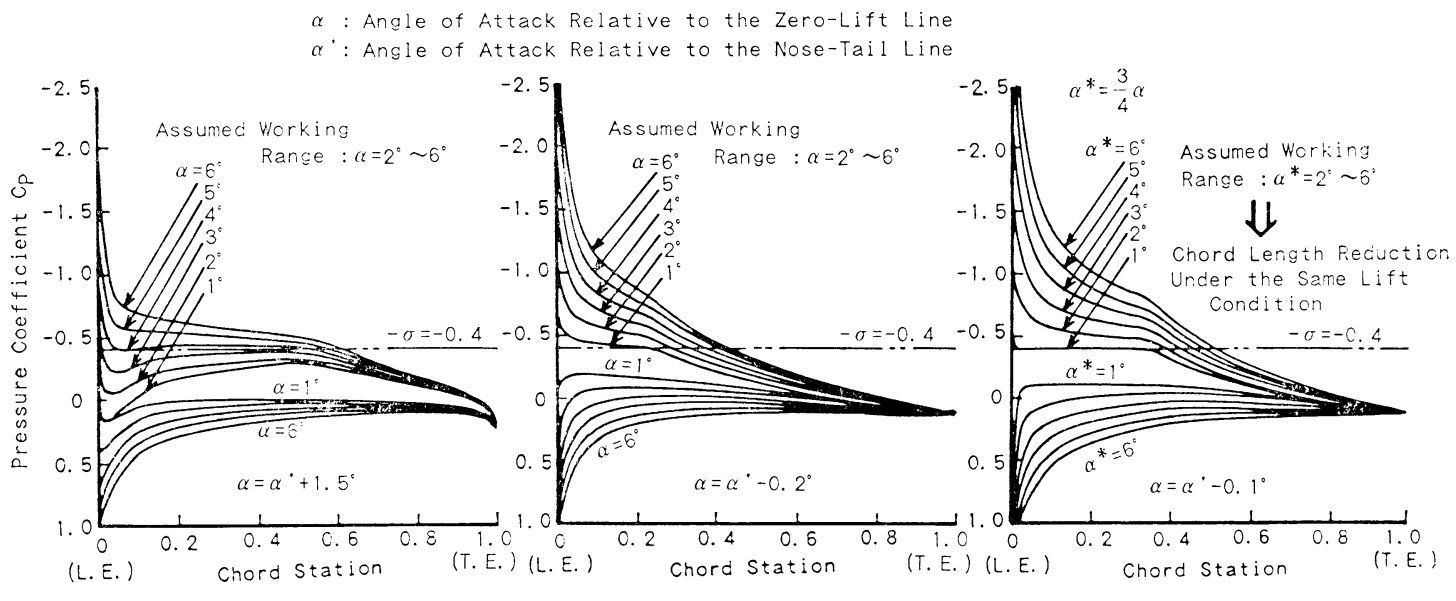

(1) MAUO. 8R (MESK)

(2) $\operatorname{TP} 710$

(3) $\operatorname{TP} 713$

Fig. 15 Pressure distribution, assumed working rarge and design cavitation number on MAL type and two new foil sections 


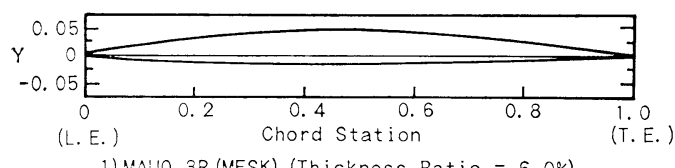

1) MAUO. 3R (MESK) (Thickness Ratio $=6.0 \%$ )

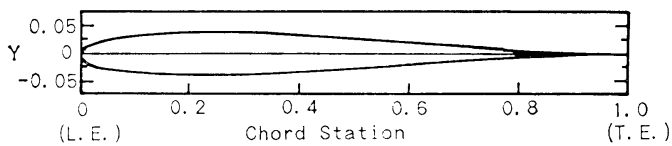

2) $T P 710$ (Thickness Ratio $=7.6 \%$ )

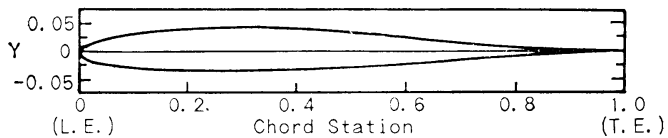

3) TP713 (Thickness Ratio $=7.6 \%$ )

Fig. 16 Shapes of the MAU type and two new foil sections

the region of the previous experiment on the $\mathrm{MAU}$ Section ${ }^{21,10)}$.

Two foil sections, TP 710 and TP 713 were finally designed and manufactured for the experiments. Their pressure distributions and section shapes are illustrated in Figs. 15 and 16 together with those of the MAU Section. In order to realize the aimed pressure distribution more exactly, TP 713 was designed by assuming that the chord length of this foil section would be reduced to $3 / 4$ of those of the other two foil sections in propeller use. Hence, the working range of TP 713 was assumed as $\alpha^{*}=2^{\circ} \sim 6^{\circ}$, introducing the new angle of attack $\alpha^{*}$ defined by $\alpha^{*}=(3 / 4) \alpha$. If $\alpha^{*}$ of TP 713 is equal to $\alpha$ of the other foil sections, then this foil with

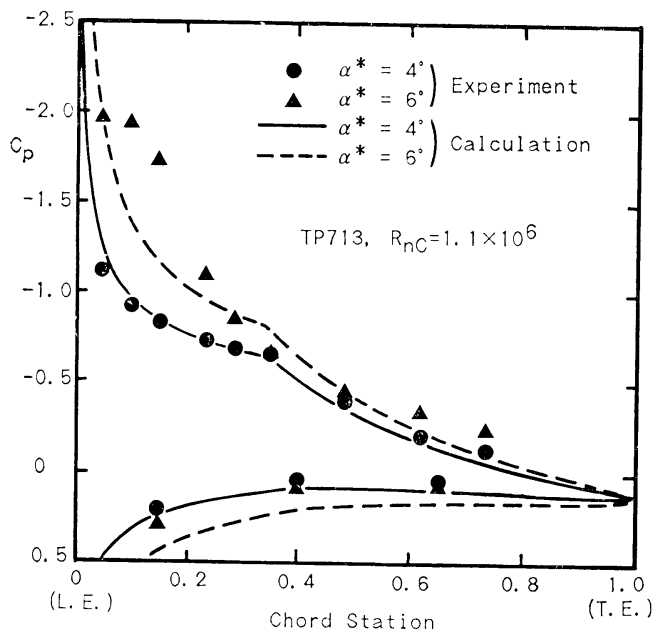

Fig. 17 Example of roncavitating pressure Uistributions with and without the bursting of leading edge separation bubble, together with the calculated caes ; TP 713, $\alpha^{*}=4^{\circ}$ and $6^{\circ}\left(\alpha=5.3^{\circ}\right.$ and $\left.8^{\circ}\right), R_{n C}=1.1 \times 10^{6}$
$3 / 4$ times the chord length of the other foils gives the same lift force as that of the other foils. The cavity size of this foil section, therefore, will be compared to that of the other sections with this chord length reduction taken into account, denoting by the superscript *. In designing the new foil sections, the flat pressure distribution was given at the angle of attack of $1^{\circ}$ with a margin of $1^{\circ}$ taken into consideration. Although both the new foil sections were thicker compared to the MAU Section in order to realize the aimed pressure distribution, it was verified theoretically and experimentally that the new foils give higher liftdrag ratio than the MAU section because of less boundary layer development ${ }^{19)}$. The rear parts of the new foil sections are too thin for practical use. However, more practical shape can be obtained by lowering the design cavitation number, i. e. by using more practical design cavitation number.

\subsection{Experimental results}

Since the experimental results of the MAU Sec-

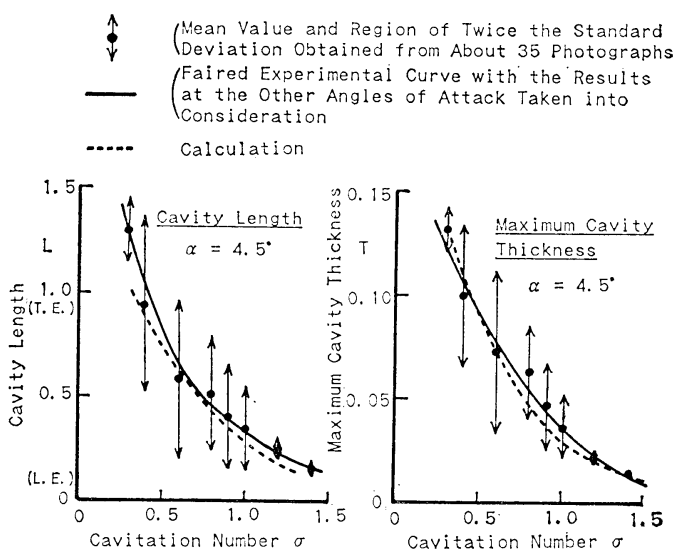

1) TP710, $\alpha=4.5^{\circ}$

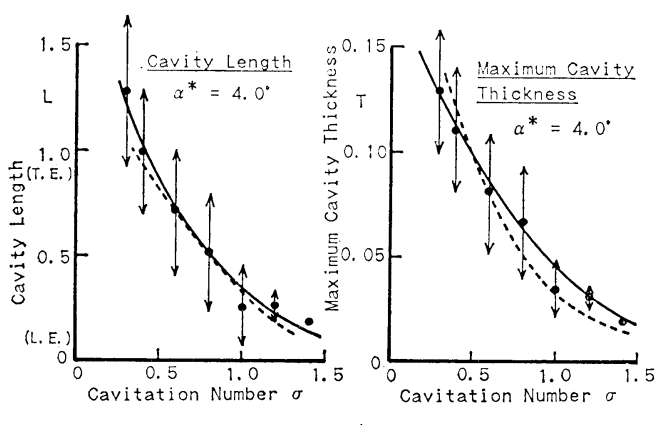

2) TP713, $\alpha^{*}=4.0^{*}\left(\alpha=5.3^{\circ}\right)$

Fig. 18 Comparison between theoretical and Experimental cavity length and thickness of the new foil sections based on cavitation number variation ; $\alpha=$ $4.5^{\circ}$ for TP 710 and $\alpha^{*}=4.0^{\circ}\left(\alpha=5.3^{\circ}\right)$ for TP 713 
tion has already been obtained ${ }^{2)}{ }^{10)}$, only the experiments using the new foil sections were performed at the Foil Test Section of the Marine Propeller Cavitation Tunnel, The University of Tokyo ${ }^{11}$. The working section is a rectangular, $600 \mathrm{~mm}$ high by $150 \mathrm{~mm}$ wide. The turbulence level of the main flow is about $0.2 \%$. Both the chord length and span width of the model foils were $150 \mathrm{~mm}$. The uniform flow velocity and the water temperature were $8.0 \mathrm{~m} / \mathrm{s}$ and about $18^{\circ} \mathrm{C}$, resulting in the Reynolds number $R_{n C}$ of about $1.1 \times 10^{6}$. Pressure measurement holes of $0.5 \mathrm{~mm}$ in diameter were drilled perpendicularly to the foil surface, 9 holes being on the upper surface and 3 holes on the lower side. The measurements of pressure distribution, incipien $\hat{\imath}$ cavitation number and cavity shape were carried out at the angle of attack $\alpha=1.5^{\circ}, 2.5^{\circ}$, $3.5^{\circ}, 4.5^{\circ}, 5.5^{\circ}$ and $6.5^{\circ}$ in the case of TP 710 , and $\alpha^{*}=1.0^{\circ}, 2.0^{\circ}, 3.0^{\circ}, 4.0^{\circ}, 5.0^{\circ}$ and $6.0^{\circ}$ in the case of TP 713, whereas the measurement of foil wake velocity to obtain the drag coefficients was made at $\alpha=2.2^{\circ}, 4.3^{\circ}$ and $6.2^{\circ}$, and $\alpha^{*}=1.9^{\circ}, 3.2^{\circ}$ and $4.7^{\circ}$ respectively because of the model foil installation reasons.

Figure 17 shows typical noncavitating pressure distributions with and without the bursting of the leading edge separation bubble, together with the calculated ones. The measured pressure distribution without the bursting agrees well with the calculated one while the result with the bursting has a constant pressure region due to the long separation bubble near the leading edge. Ranges of the angle of attack with the bursting, judged from the measured pressure distributions, were $\alpha \geqq 4.5^{\circ}$ for the MAU Section, $\alpha>6.5^{\circ}$ for TP 710 and $\alpha^{*} \geqq 5.0^{\circ}$ for TP 713. These ranges agree approximately with the theoretical predictions based on the boundary layer calculations.

Figure 18 denotes the variation of cavity length and thickness due to cavitation number in the case of $\alpha=4.5^{\circ}$ for TP 710 and $\alpha^{*}=4.0^{\circ}$ for TP 713 . In the calculation the cavity tip was set to agree with the leading edge of the foil and also in the experiment the cavity was generated from the leading edge. The experimental values were obtained by analyzing about 35 photographs taken at each test condition. The cavity length and thickness were obtained from the photographs taken in the top and side views, respectively. Although the cavities became very unsteady below certain cavitation numbers as denoted by the standard deviations, the results obtained from the present steady nonlinear theory agree well with the mean values.

The cavity volume at each test condition was obtained by integrating the thickness distribution of a representative cavity selected from the photographs with the faired experimental curves, e.g. denoted by the solid lines in Fig. 18, taken into consideration. Figure 19 shows the cavity volume variation due to the angle of attack using the cavitation number as a parameter. It can be said that the quantitative agreement between the theory and

\begin{tabular}{|c|c|c|c|c|c|}
\hline & \multicolumn{4}{|c|}{ Cavitation Number $\sigma$} & \multirow{2}{*}{$\begin{array}{l}\text { Best Fit by Quadratio } \\
\text { Expression }\end{array}$} \\
\hline & 0.4 & 0.6 & 0.8 & 1.0 & \\
\hline Experiment & - & $\Delta$ & a & $\nabla$ & $\longrightarrow$ \\
\hline Calculation & 0 & $\Delta$ & 口 & $\nabla$ & $\cdots \cdots$ \\
\hline
\end{tabular}

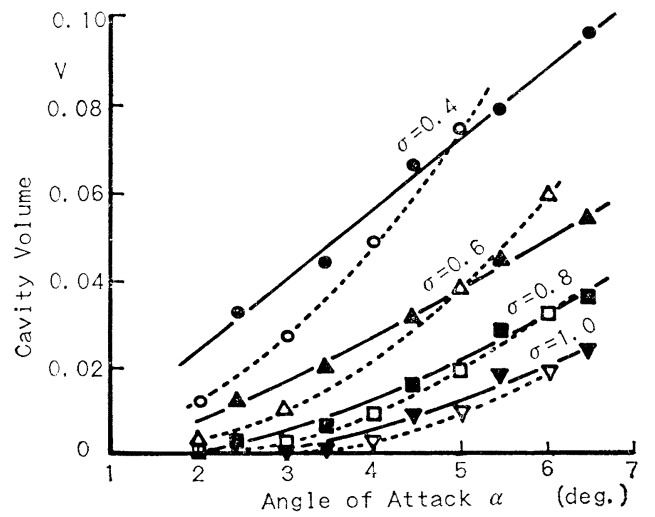

1) $T P 710$

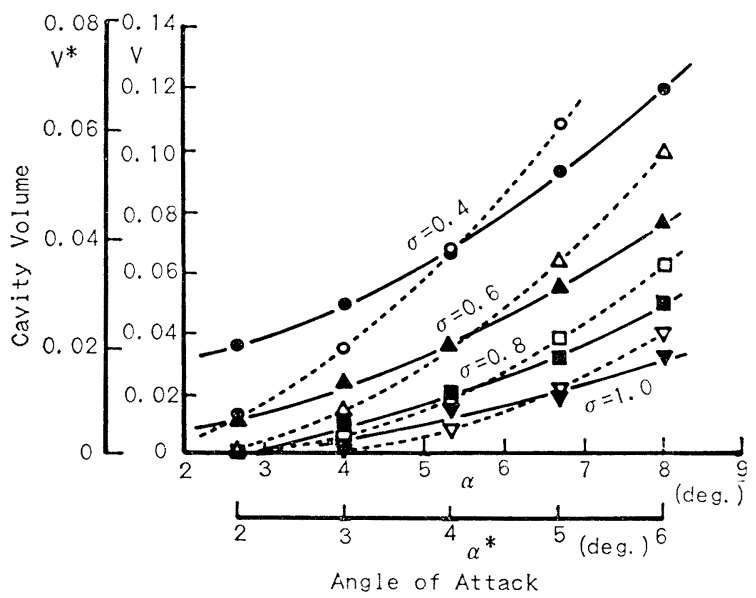

2) TP7 13

Fig. 19 Comparison between theoretical and experimental cavity volume based on angle of attack variation 
the experiment is fairly good in both the foil sections. However, the inclination of the theoretical curves, which is important in this research, is higher than that of the experimental ones. Consequently, the cavity volume variation obtained by the experiments became less than predicted. As shown in this figure, both the experimental and theoretical values can be well approximated by the quadratic expressions. Therefore, comparison on cavity volume among the foil sections will be performed using these curves.

Figure 20 shows the comparison of experimental cavity volume variation due to the angle of attack among all the foil sections. Since the curves of

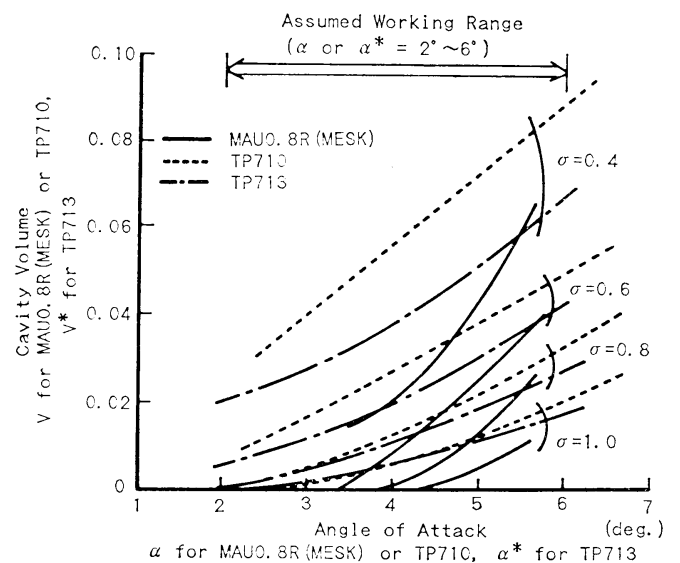

Fig. 20 Comparison of the experimental cavity volume variation due to the angle of attack among all the foil sections

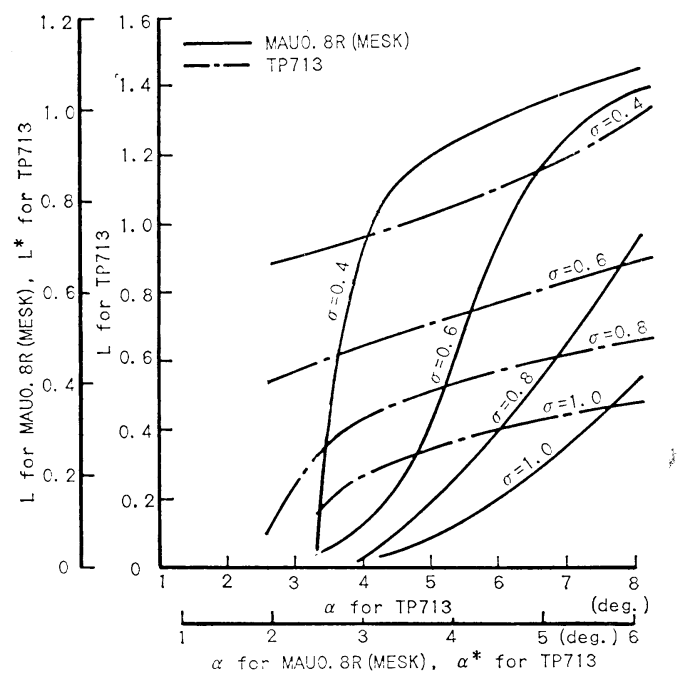

Fig. 21 Comparison of the experimental cavity length variation due to the angle of attack between MAU0.8R (MESK) and TP 713

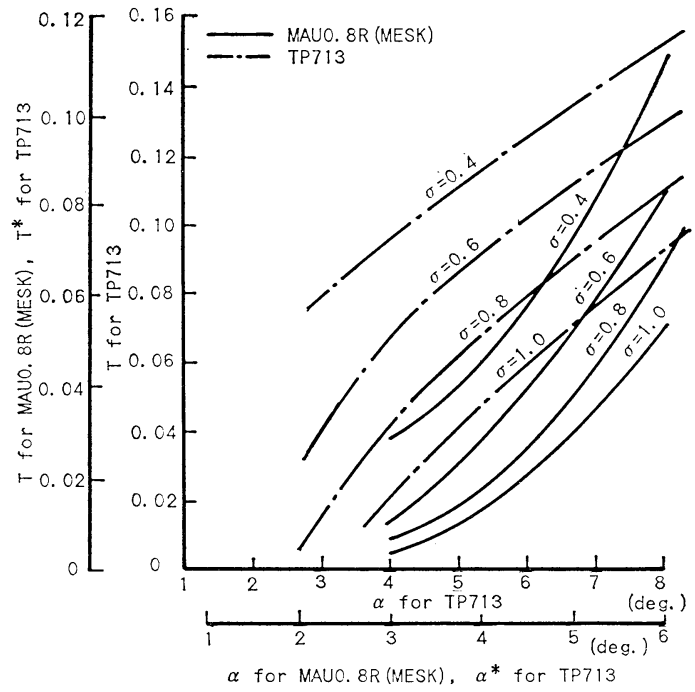

Fig. 22 Comparison of the experimental cavity thickness variation due to the angle of attack between MAU0.8R (MESK) and TP 713

the MAU Section were obtained by re-analyzing the data using the method in this paper, they are slightly different from those shown in the previous papers $^{2), 10)}$. The cavity volume variation of the new foils is much lower than that of the MAU Section although the cavity becomes larger. It can be seen from the comparison shown in Figs. 21 and 22 that the reduction of cavity volume vari. ation is ascribed to less variation of both the cavity

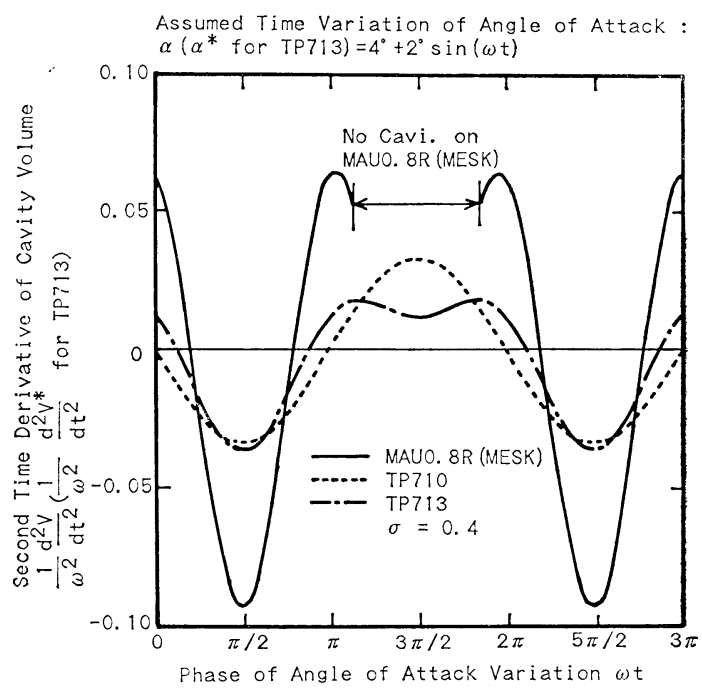

Fig. 23 Variation of 2 nd time derivative of the experimental cavity volume with the assumption of sinusoidally changing angle of attack ; $\sigma=0.4$ 


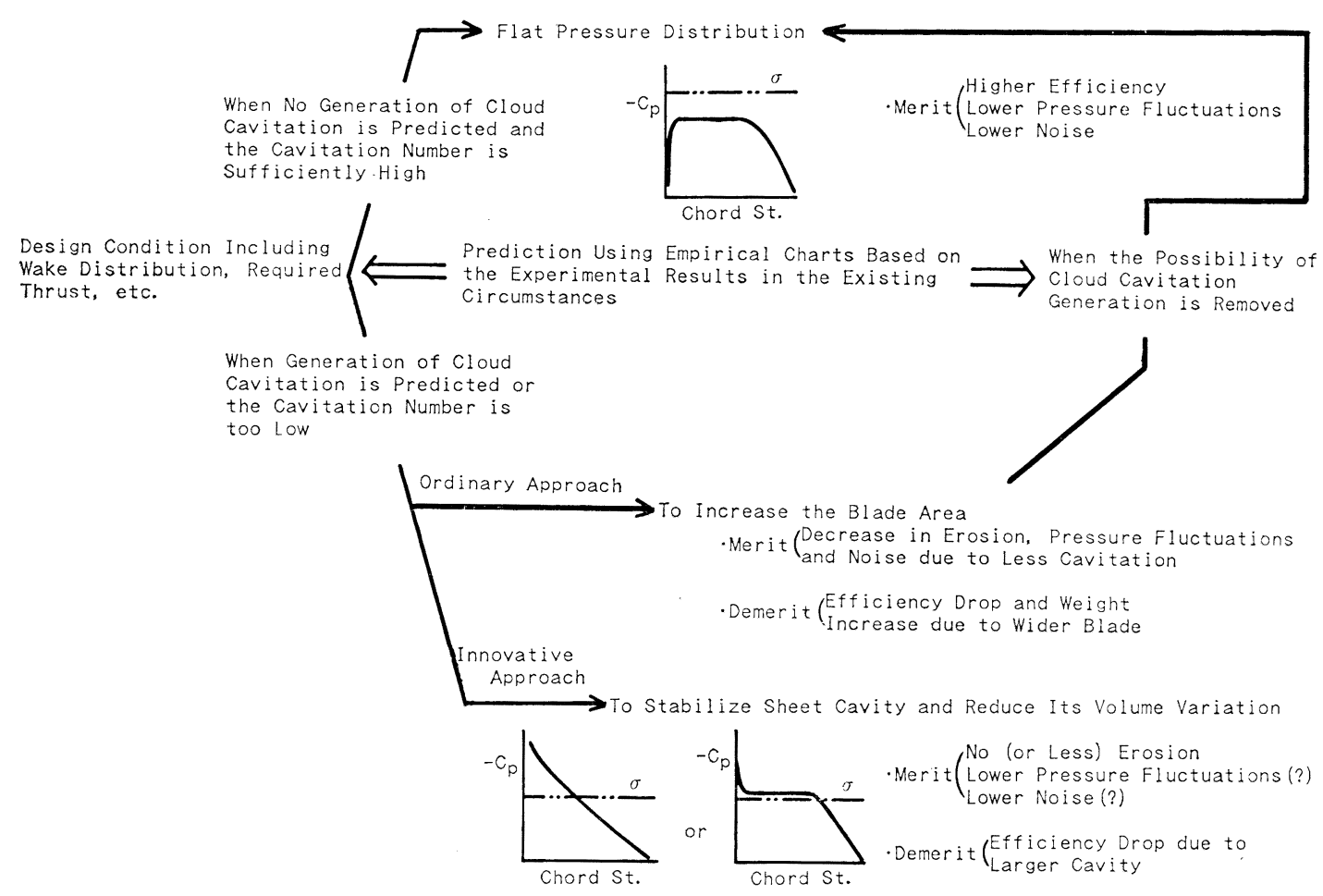

Fig. 24 Relation among the design concept of flat pressure distribution, the ordinary approach to increase the blade area and the present design concept

length and thickness.

In order to see the effect of the new foil sections more practically, 2 nd time derivative of the cavity volume which mainly causes the pressure fluctuations due to cavitation was evaluated with the assumption of sinusoidally changing angle of attack :

$$
\alpha\left(\alpha^{*} \text { for } \operatorname{TP} 713\right)=4^{\circ}+2^{\circ} \sin (\omega t)
$$

Comparison at the cavitation number of 0.4 is shown in Fig. 23. The amplitudes of TP 710 and TP 713 values are respectively 0.42 and 0.34 times as large as that of the MAU Section one.

\section{Discussion on the Significance of the Present Design Concept}

The authors showed the effectiveness of the flat pressure distribution in the previous reports ${ }^{1)}{ }^{3)}$ and proposed here a new concept to stabilize sheet cavitation and reduce its volume variation. It is considered better to clarify the relation among the above two design concepts and the ordinary approach. As shown in Fig. 24, flat pressure distribution should be adopted to increase the efficiency and decrease the pressure fluctuations and noise when no generation of cloud cavitation is predicted and the cavitation number is sufficiently high. The first problem is to predict the cloud cavitation occurrence. Since the cloud cavitation occurs at the final stage of cavity variation, highly accurate calculation of pressure distribution including the effect of unsteady cavitation might be required to predict its occurrence purely theoretically. Hence, it is considered most practical within the present stage of the knowledge to use empirical charts based on the experimental results ${ }^{20)}{ }^{22}$.

When the generation of cloud cavitation is predicted or the cavitation number is too low, it is usual to increase the blade area in order to lessen the erosion, pressure fluctuations and noise by reducing the cavity amount. However, this approach involves the efficiency drop and the weight increase due to larger blade area. On the other hand, the present innovative approach can suppress the erosion and reduce the pressure fluctuations and noise without the weight increase although the possibility is not fully verified yet. The problem in this approach is the efficiency drop due to larger cavity which is a factor to be compared with the above demerits of the ordinary approach. Regarding the effect of cavitation on the efficiency, the authors recently obtained interesting experimental results (unpublished work). As another research subject in the authors' laboratory, a foil section with similar pressure distribution to those of the present sections was tested to investigate a possibility of drag reduction due to the slip effect 
of sheet cavity. The results showed that the liftdrag ratio of cavitating condition exceeded that of noncavitating one in a certain range of cavitation number. It is expected, therefore, that the efficiency drop due to larger cavity might be very slight or even the efficiency "increase" might be obtained if well clesigned.

\section{Conclusions}

Pressure distribution to stabilize sheet cavitation and reduce its time variation was pursued as a method which becomes effective when the propeller working condition is severe and likely to give harmful cloud cavitation.

First, two propellers with the flat and the triangular pressure distributions were designed and tested at a working condition where the original MAU type propeller generated cloud cavitation and erosion. The results obtained are as follows:

(1) As expected, the triangular pressure distribution succeeded in suppressing the cloud cavitation completely while the flat one failed.

(2) However, the triangular pressure distribution could not reduce the pressure fluctuations or the time variation of cavity volume, although almost the same levels as the MAU type one were kept in both the pressure fluctuations and noise in spite of the cavity volume being about three times as large as that of the MAU type propeller.

Then a two-dimensional and quasi-steady study on foil sections was performed to obtain a prospect for the pressure distribution which realizes both the stabilization of sheet cavity and the reduction of cavity volume variation. The following results were obtained:

(1) The variation of cavity volume due to the angle of attack was much lessened by the pressure distribution with a negative peak at the leading edge and a region of constant pressure which is lower than the vapor pressure. The amplitudes of 2nd time derivative of cavity volume on the new foil sections obtained by assuming sinusoidal variation of the angle of attack, were about 0.4 times as large as that of the MAU type foil section. This result shows that such pressure distribution has a possibility of not only suppressing cloud cavitation but also reducing pressure fluctuations to less than half of that of the MAU type one. It is desired that the present result on two-dimensional foils will be verified by a propeller study.

(2) The cavity size predicted by the nonlinear cavity flow theory agreed well with the experiment. The theory, however, overestimated the variation of cavity volume due to the angle of attack.

\section{Acknowledgments}

The authors express their sincere gratitude to the staffs in Akishima Laboratories (Mitsui Zosen) Inc. and Highspeed Dynamics Laboratory, Department of Naval Architecture, The University of Tokyo for their kind help in conducting the experiments. The authors are indebted also to Mr. K. Inaba for his collaboration in the present propeller study. The authors' gratitude is extended to Mrs. M. Hirokawa, Miss Y. Maeda and Mr. T. Komura for their typewriting and drawing in preparing the manuscript.

This research was partly supported by the Grantin-Aid for Scientific Research of the Ministry of Education, Science and Culture. The HITAC M$682 \mathrm{H}$ System at the Computer Centre, The University of Tokyo was used for the calculations in this research.

\section{References}

1) Yamaguchi, H. et al.: "Development of Marine Propellers with Better Cavitation Performance (1st Report)", Journal of SNAJ, Vol. 158 (1985) (in Japanese).

2) Yamaguchi, H. et al.: "Development of New Marine Propellers with Improved Cavitation performance”, Proc. Int. Symp. Propeller and Cavitation, Wuxi, China, CSNAME, 1986.

3) Yamaguchi, H. et al.: "Development of Marine Propellers with Better Cavitation Performance (2nd Report)", Journal of SNAJ, Vol. 163 (1988).

4) Eppler, R. and Somers, D. M.: “A Computer Program for the Design and Analysis of Low-Speed Airfoils", NASA TM80210, 1980.

5) Ito, T. et al.: "Calculation of Unsteady Propeller Forces by Lifting Surface Theory", Symp. Hydrodynamics of Ship and Ofishore Propulsion Systems, Oslo, 1977.

6) Ligtelijn, J. Th. and Kuiper, G.: "Intentional Cavitation as a Propeller Design Parameter", Proc. PRADS 83, Tokyo \& Seoul, SNAJ \& SNAK, 1983.

7) Yamaguchi, H. and Kato, H.: "Nonlinear Theory for Partially Cavitating Hydrofoils", Journal of SNAJ, Vol.152 (1983) (in Japanese).

8) Yamaguchi, H. et al.: "Nonlinear Theory for Partially Cavitating Hydrofoils (2nd Report)", Journal of SNAJ, Vol.154 (1983) (in Japanese).

9) Yamaguchi, H. and Kato, H.: "On Application of Nonlinear Cavity Flow Theory to Thick Foil Sections", Proc. 2nd Int. Conf. Cavitation, Edinburgh, IMechE, 1983.

10) Yamaguchi, H. and Kato, H.: "Development of a Foil Section with Improved Cavitation Performance", Journal of SNAJ, Vol. 154 
(1983) (i.: Japanese).

11) Kato, H. et al.: "New Marine Propeller Cavitation Tunnel at The University of Tokyo, Its Design Concept and Special Features", Journal of SNAJ, Vol.150 (1981) (in Japanese).

12) Sugatani, A. and Inaba, K.: "Effect of Blade Surface Pressure Distribution on Propeller Cavitation Performance", Graduate Thesis, Department of Naval Architecture, The University of Tokyo, 1986 (in Japanese).

13) Kato, H. et al.: "A Comparison and Evaluation of Various Cavitation Erosion Test Methods", Proc. Symp. Cavitation Erosion in Fluid Systems, Boulder, ASME, 1981.

14) Hoshino, T.: "Estimation of Unsteady Cavitation on Propeller Blades as a Base for Predicting Propeller-Induced Pressure Fluctuations", Journal of SNAJ, Vol. 148 (1980).

15) Izumida, $Y$. et al.: "The Relationship Between Characteristics of Partial Cavitation and Flow Separation", Proc. 10th IAHR Symp., Tokyo, 1980.

16) Hess, J. L. and Smith, A. M. O.: "Calculation of Potential Flow about Arbitrary Bodies", Progress in Aeronautical Sciences, Vol. 8 (1966).

17) Cebeci, T. and Bradshaw, P.: "Momentum Transfer in Boundary Layers", Hemisphere Publishing Corp., McGraw-Hill Book Co., 1977.

18) Takahashi, M. et al.: "The Cavitation Characteristics of MAU Type Propeller (1st, 2nd and 3rd Report)", Journal of SNAJ, Vol. 141 (1977), Vol. 143 (1978) (in Japanese).

19) Kamijo, A. and Honda, T.: "A Study of Foil Sections with Less Cavity Volume Variation", Graduate Thesis, Department of Naval Architecture, The University of Tokyo, 1987 (in Japanese).

20) Tanibayashi, H. and Nakanishi, M.: "On the Method of Cavitation Tests for Prediction of Tip Erosion of Propeller", Journal of SNA J, Vol. 133 (1973).

21) Lindgren, H. and Bjärne, E.: "Studies of Propeller Cavitation Erosion", Conf. Cavitation, Edinburgh, IMechE, 1974.

22) Izumida, Y.: "Study on Propeller Design Method urder Cavitating Condition (1st and 2nd Report)", Journal of SNAJ, Vol.155 (1984), Vol. 160 (1986) (in Japanes:)

\section{Appencix}

After the publication of the previous (2nd) report ${ }^{31}$, the authors found an error due to carelessness in Fig. 24. The ordinate scales were twice the actual, viz. that figure should be replaced by the following one.

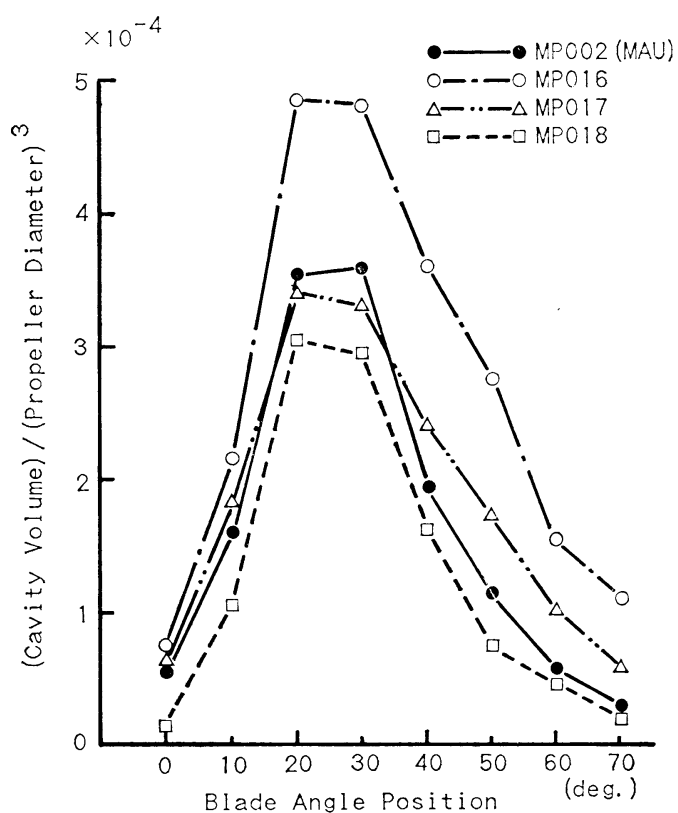

Fig. 24 (Revised) Comparison of cavity volume variation 